\title{
Innovative Applications Mode of Network Learning Space in Exercise Physiology based on Ubiquitous Learning
}

\author{
https://doi.org/10.3991/ijet.v14i04.10117 \\ Jie Kong \\ Jinling Institute of Technology, Nanjing, China \\ jiekong2000@126.com
}

\begin{abstract}
With continuous development of internet technology, the concept of ubiquitous learning and network learning space have received more and more attention from scholars, and gradually become the research focuses. College classroom has turned to network teaching from traditional teaching. In this study, literature review and case study were combined with ubiquitous learning and network learning space construction to systematically discuss classification and concept models of network learning space under the perspective of ubiquitous learning. Meanwhile, four models based on network learning space were proposed, and flipped classroom network teaching model was applied in the course of Exercise Physiology. The study showed that, the model has the good teaching effect in course teaching. It not just improves students' interest, but also lays a foundation for popularizing the teaching mode.
\end{abstract}

Keywords - Ubiquitous learning; network learning space; flipped classroom; exercise physiology

\section{Introduction}

Ubiquitous learning usually refers to the learning activity that anyone can carry out with any equipment anytime and anywhere. Learners are required to acquire learning resources and services with nay equipment. It is considered as a new learning method which contains rich learning theories and education significance, and makes learning any knowledge anytime and anywhere become possible [1].

With rapid development of internet technology, "Internet +" with prominent technical features and unique intelligent learning theory not merely drives economic development and generates revolutionary influence on teaching and learning mode, but also invisibly provides infinite possibilities for ubiquitous learning [2]. With continuous update and development of big data, cloud computing and "Internet +", they have become an irresistible force in current society. Hence, network learning space emerges, and becomes a new force to drive education development [3]. The in-depth development and application of network learning space teaching mode become the new requirements of education industry under internet background. Features of ubiquitous 
learning organically tally with functions of network learning space to support and enhance deep application and integrated innovation of space, which provides the favorable perspective and opportunity for innovative application of network learning space.

\section{State of the Art}

Network learning space is conceptually classified into generalized network learning space and narrow network learning space. In a broad sense, network learning space refers to the learning activities under network support environment, such as virtual learning community, MOOC, and online course. In a narrow sense, network learning space refers to network learning environment which integrates learning resources, tools, services, communities and management under the background of "Internet + " [4]. The development of college network learning space in foreign countries is earlier than that in China. So far, network learning space has been promoted and applied widely in foreign countries, and successful application cases have emerged in colleges. For example, some private universities in US utilized network platform to provide online services. Students can achieve online tuition fee payment, course study, assignment exchange and examination assessment through this platform [5]. British open universities have gained the significant effect in the aspect of network learning space application [6]. The teaching effect from design and promotion of network learning space can be compared with face-to-face teaching. The biggest advantage of network learning platform is that it owns independent learning tools and supporting units. Students can freely plan their learning paths through the platform, and customize their learning schedule. Besides, the problems of students in the learning process can be properly adjusted on the network learning platform. Walkington et al. [7] investigated the learning space by combining research journals of two geography undergraduates. Wikis provides postgraduate reviewers with the special space to jointly develop constructive feedbacks to authors creating a supportive network learning environment. The results verified that, students could greatly improve writing enthusiasm through learning in network learning space. Hong et al. [8] proposed to utilize neural network algorithm to construct network learning space. In addition, they proposed to develop an online real-time warning system with MLP-EKFQ to foresee river temperatures influenced by the discharge of cooling water $1 \mathrm{~km}$ downstream of a thermal power station, from real time to $2 \mathrm{~h}$ ahead. The experiment proved the network learning space has great development potential, and is suitable for teaching. In addition, Jones Online University [9], Europe progress school [10], comprehensive media laboratory of American Denison University and University of Venice [11] have gained great achievements in terms of college network learning space construction.

Domestic research on network learning space is later than overseas research. With internet development, the development of network learning space has gradually become the research focus. Relevant researches indicate that, as many as 401 papers can be found by searching the key word "network learning space" in 2010-2016. It thus can be seen that, there are more and more researches on network learning space. 
Meanwhile, the researches on network learning space mainly focus on the concept, function, construction, design and application of network learning space. With regard to network learning space construction, Zhu [12] divided network learning space into space structure, support service, access environment and user ability, and emphasized the important role of big data analysis. He proposed personal learning space information model and established it from student, resource, situation, activity and relation to better guide teachers to apply network space for teaching effect improvement. Learners improved learning efficiency with the designed application mode. About the construction and application of college network learning space, various colleges have gradually started construction of network learning space, promoted and applied it in recent years. For example, Anyang Normal University promoted network learning space construction, planning, implementation, application and promotion step by step, in the hope of reaching the better effect and providing reference for other colleges. Construction, promotion and application of network learning space play an important role in high-level talent education.

Network learning space has become a research field that researchers extensively pay attention to and study, and certain achievements have been gained in many aspects. Such learning platform not just makes students gain learning resources and changes students' learning mode, but also enhances students' learning interest and provides favorable conditions for their ubiquitous learning. Although the study on network learning space is developing at a rapid speed, certain problems exist in the development process. For instance, the development quality of network learning space needs to further improve, and its application is still in the primary stage. There are few innovations of its application modes. All these need improvement to better guide students' learning.

\section{Construction of Network Learning Space based on Ubiquitous Learning}

\subsection{Overview of ubiquitous learning}

Ubiquitous learning is a pervasive learning mode. Students can learn and acquire any information anytime and anywhere in the virtual space and under the support of computer. Based on the understanding of ubiquitous learning, the researcher considers that it mainly has four features: applicability, integrity, interactivity and situation. Ubiquitous learning process achieves organic integration of tools, modes and achievements. Besides, learners can acquire required information fast by the diversified network platforms, and achieve multiple kinds of online exchanges. The environment and modes are flexible. Thus, ubiquitous learning plays a great role in improving learning quality and quality. 


\subsection{Construction of network learning space based on ubiquitous learning}

Classification frame of network learning space: Network learning space contains three dimensions: learning culture, resource form and application occasion [15], as shown in Fig.1. Learning culture dimension includes society and individual. Autonomy and heteronomy are the cultural dimensions of governance right allocation of network learning space. Autonomy is self-centered and means to acquire information according to individual needs and own the absolute control right for content organization, process implementation and effect evaluation. Heteronomy means to others control numerous aspects of information acquisition, and it belongs to two poles in the learning space, but the two are balanced. In the design of learning culture dimension, several factors should be taken into account, such as learning activity content, goal, students' demand and relevant background. Based on these factors, accurate orientation shall be conducted in the space dimension of individual and society. Measurement should be based on the control right of autonomy and heteronomy. In accordance with resource form, learning resources are classified into static and dynamic learning resources according to the variability. One type is the preset resource before learning, and the other type is dynamically generated resource in the learning process. The two depend on each other and transform mutually. According to the application occasions, learning resources are classified into regular and irregular resources. Regular resources usually own the set goals, and are learned in a well-organized way. Irregular resource is a kind of non-organized and course-free learning mode. The two have respective features and application occasions. They are not opposite but encompassing.

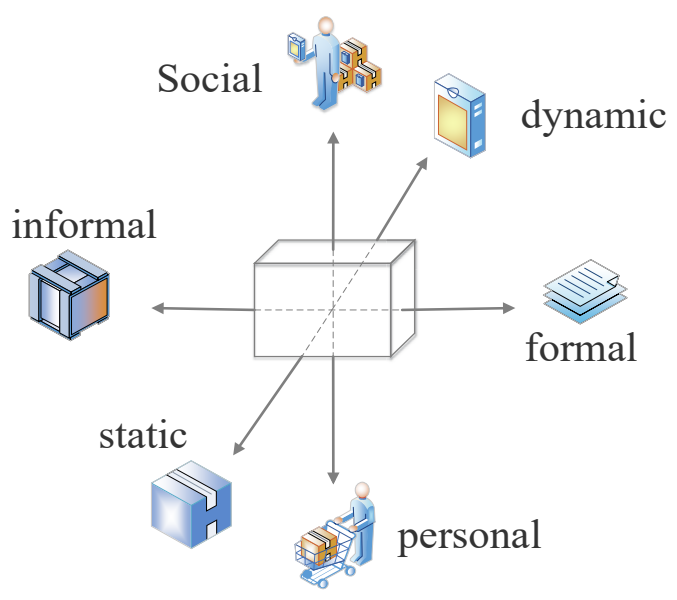

Fig. 1. Classification frame of network learning space

Conceptual model: Under the support of relevant theories and internet technology, the conceptual model of network learning space forms under the perspective of ubiquitous learning, as shown in Fig.2. The model is based on the ideas of ubiquitous 
learning, teaching design, inclusive education and wisdom education. The formation of these ideas has strong guiding significance for construction of network learning space, which can prevent the defect of only paying attention to technology. Meanwhile, technical support plays a great role for construction of network learning space. Cloud computing, big data and analysis technology provide strong support for ubiquitous learning and effectively improve learning efficiency. Network learning space is not constructed by single element, but integrates some formal, informal, individualized and socialized learning modes. Organic integration and application of these modes achieve seamless fusion of learning.

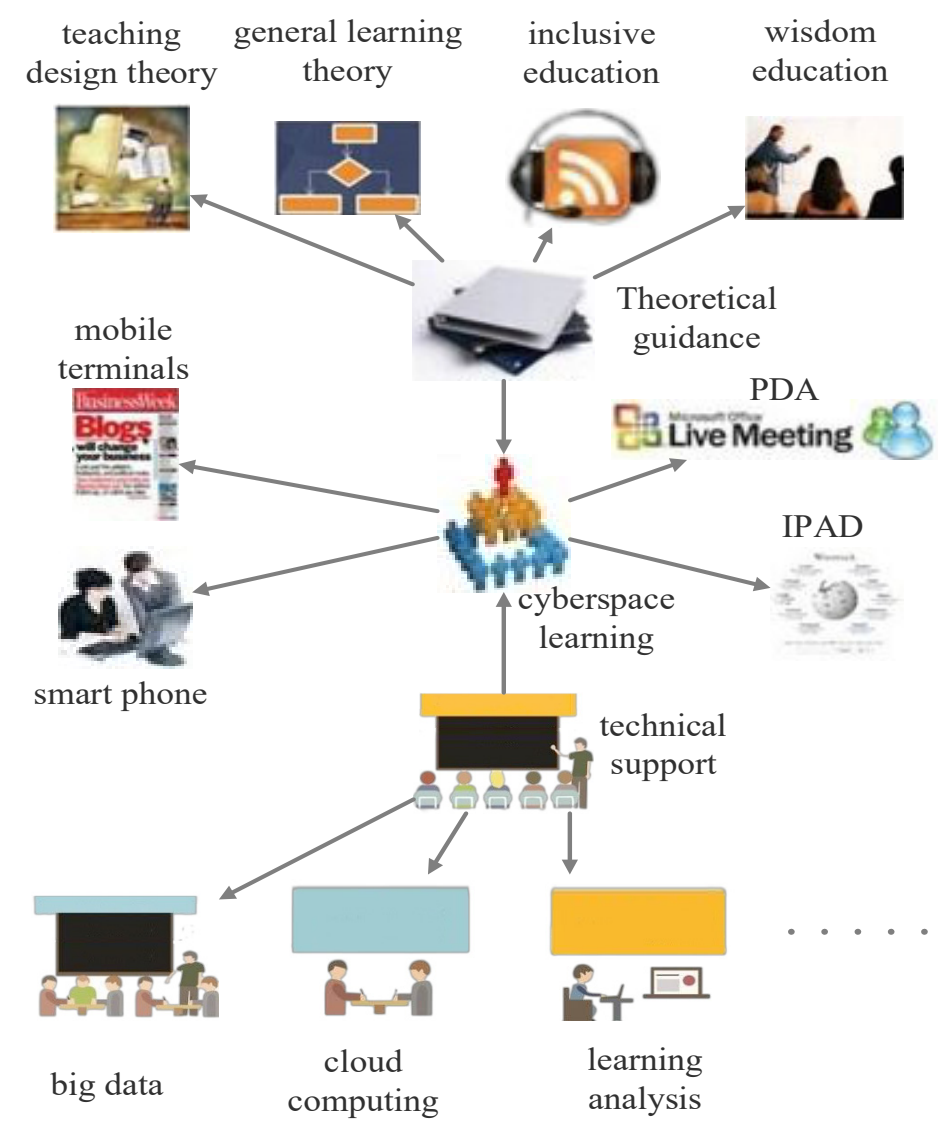

Fig. 2. Conceptual model of network learning space based on ubiquitous learning

Composition and structure: With the help of learning support service platform, network learning space provides suitable learning space for every learner. Through four elements role, content, toll and process information space, it exerts the functions of four platforms (network, management, social contact and service support) and reaches the objective with the help of cloud computing, big data and learning analysis. Four elements, four platforms and advanced technologies of network learning space 
allow learners to acquire knowledge and information they want through network learning space, to form social network in the learning space, and establish net-type relations with classmates or teachers. These further promote knowledge construction, cultivate and improve problem solving and analyzing ability. Lastly, individuals develop and form collective wisdom. The composition and structure are shown in Fig.3.

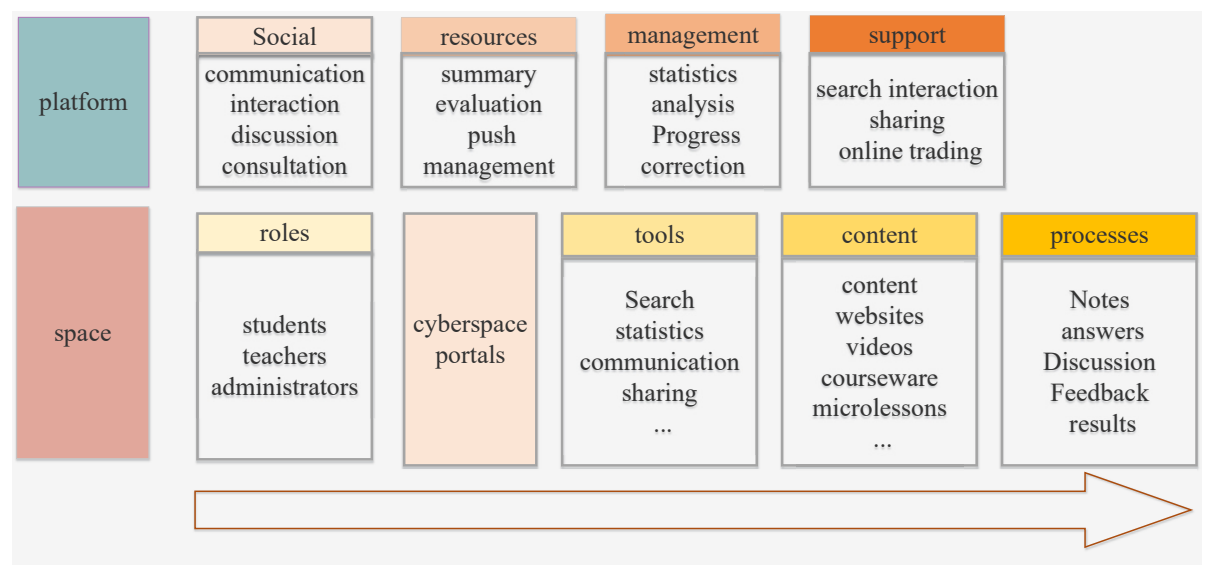

Fig. 3. Composition and structure of network learning space based on ubiquitous learning

\section{Innovative Teaching Mode}

\subsection{Flipped classroom mode based on network learning space}

Flipped classroom mainly embodies "flipped". Compared with traditional classroom, flipped classroom means the teacher-centered teaching mode is flipped to student-centered learning mode, as shown in Fig.4. Classroom center flipping is just a superficial phenomenon. The deeper-level flipped classroom refers to the change of learning mode with multiple teaching methods such as multimedia video and PPT and with the help of network learning space. The original explanation by the teacher and homework after class are changed to pre-class micro-video study and difficulty solving under the guidance of the teacher. In this way, students really become the subject of the classroom and change to active learning from passive reception. This is the change brought by flipped classroom mode based network learning space. Compared with traditional classroom, flipped classroom puts forward higher requirements for teachers, and the role of teachers also change. Teachers need to answer students' questions more professionally and deeply.

The application of flipped classroom mainly includes three aspects. Firstly, microcourse teaching video is produced. PPT is used to produce the video. Students preview the course content through the micro-course video, and mark the doubts for the targeted learning. Secondly, after the micro-course video is prepared well, it is necessary to organize and plan the classroom activity. For learning content push and class- 
room content arrangement, some social platforms can be used to push videos, establish learning group and let students exchange before the class. In one word, multiple channels are applied for classroom teaching. After pre-class learning is completed through the established mode, the major task in classroom is to answer questions by the teacher and students deeply learn relevant knowledge. Finally, teaching effect of flipped classroom is evaluated from multiple aspects, such as pre-class independent study, classroom discussion participation and after-class assignment completion. The evaluation mechanism is established and corresponding improvement measures are taken for the results to achieve continuous improvement of academic performance.

The application of flipped classroom in Exercise Physiology teaching contributes to more three-dimensional and visual body science and enhancing students' hobbies and interests. Besides, it also meets students' demand for professional knowledge. The flipped classroom can enhance students' interest, cultivate students' exchange ability and learning initiative and improve teachers' professional ability so as to enhance students' problem solving ability.

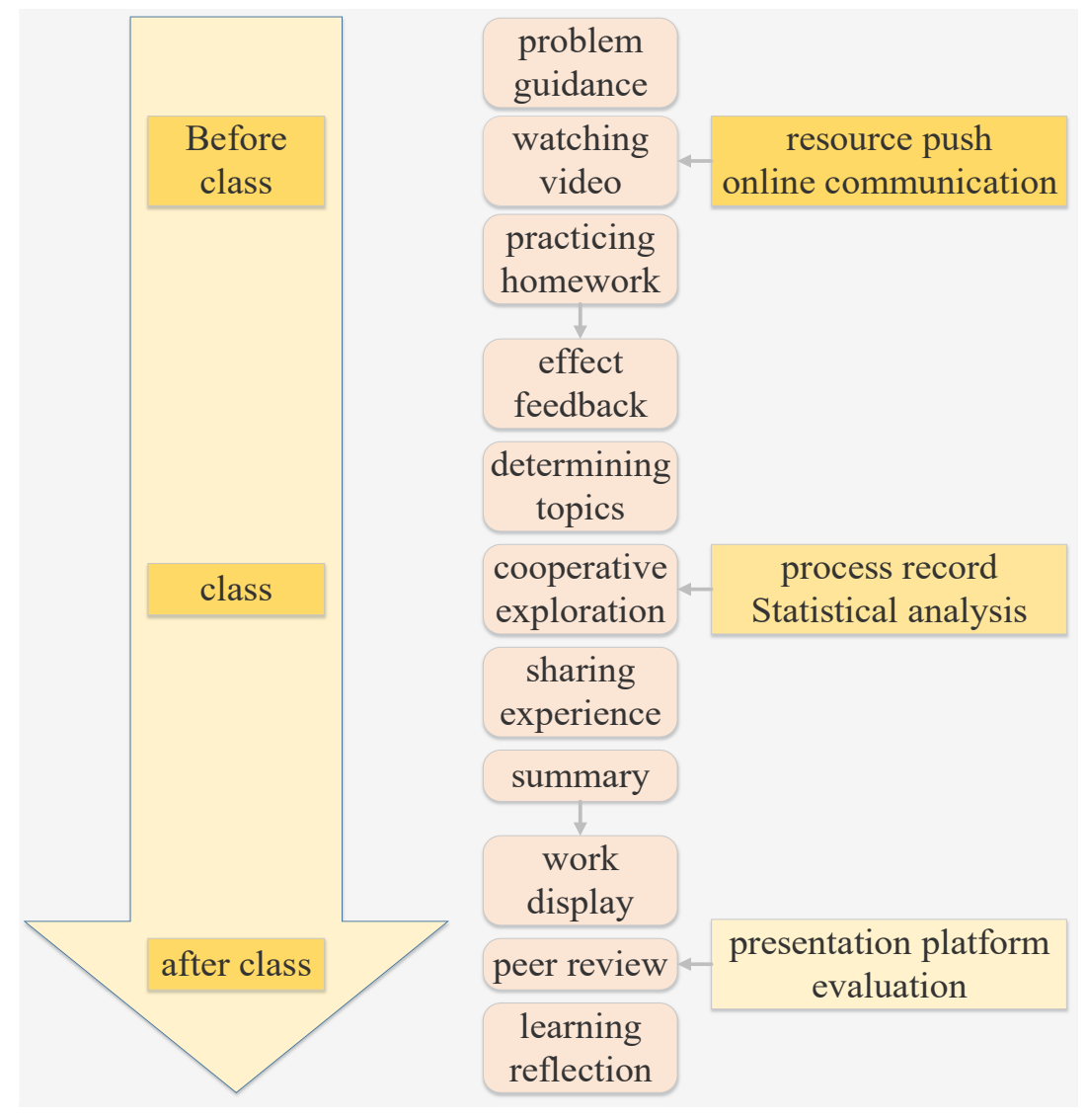

Fig. 4. Flipped classroom teaching mode based on network learning space 


\subsection{Affective and cognitive factor integration mode based on network learning space}

Based on network learning space, scholars organically integrate affective factors and cognitive factors, mine the action rules of cognitive interaction and affective interaction and give full play to synergistic effect of mutual promotion of emotion and cognition in network learning space. Based on this theory, the model of "affective and cognitive interaction level tower" forms, as shown in Fig.5. The model includes four levels and corresponding four elements which interact complexly, but have certain rules.

\begin{tabular}{|c|c|c|c|c|c|}
\hline \multirow[t]{2}{*}{ Abstra } & $\begin{array}{l}\text { conceptual } \\
\text { interaction }\end{array}$ & $\begin{array}{l}\text { old and new } \\
\text { knowledge }\end{array}$ & thought & $\begin{array}{c}\text { reflection } \\
\text { layer }\end{array}$ & advanced \\
\hline & & $\begin{array}{l}\text { student and education } \\
\text { student and student } \\
\text { community }\end{array}$ & social & $\begin{array}{c}\text { conversation } \\
\text { layer }\end{array}$ & \\
\hline cognition & $\begin{array}{l}\text { operation } \\
\text { interaction }\end{array}$ & $\begin{array}{l}\text { student and resources } \\
\text { student and media }\end{array}$ & mental & $\begin{array}{l}\text { behavior } \\
\text { layer }\end{array}$ & emotional \\
\hline concrete & & $\begin{array}{l}\text { Media interaction } \\
\text { characteristics }\end{array}$ & physiological & instinct layer & low-level \\
\hline
\end{tabular}

Fig. 5. Model of "affective and cognitive interaction level tower"

Based on the learning view and significance construction generated on the basis of double-subject teaching thought and knowledge, "affective and cognitive integration" network teaching mode is constructed by refereeing to relevant research results, as shown in Fig.6. "Affective and cognitive integration" network teaching mode is mainly composed of cognitive elements and affective elements. With the help of network teaching platform, students and teachers carry out human-computer interaction. The mode supports teachers and students to cognize information so as to form two cognitive elements. Meanwhile, two corresponding affective elements are produced on the basis of two cognitive elements. Thus, four core elements form. They intersect and form three basic relations. "Affective and cognitive integration" network teaching mode intensively embody four cores and three basic relations. At the same time, the interaction between teachers and students can adjust human-computer interaction, and thus a closed type forms. 


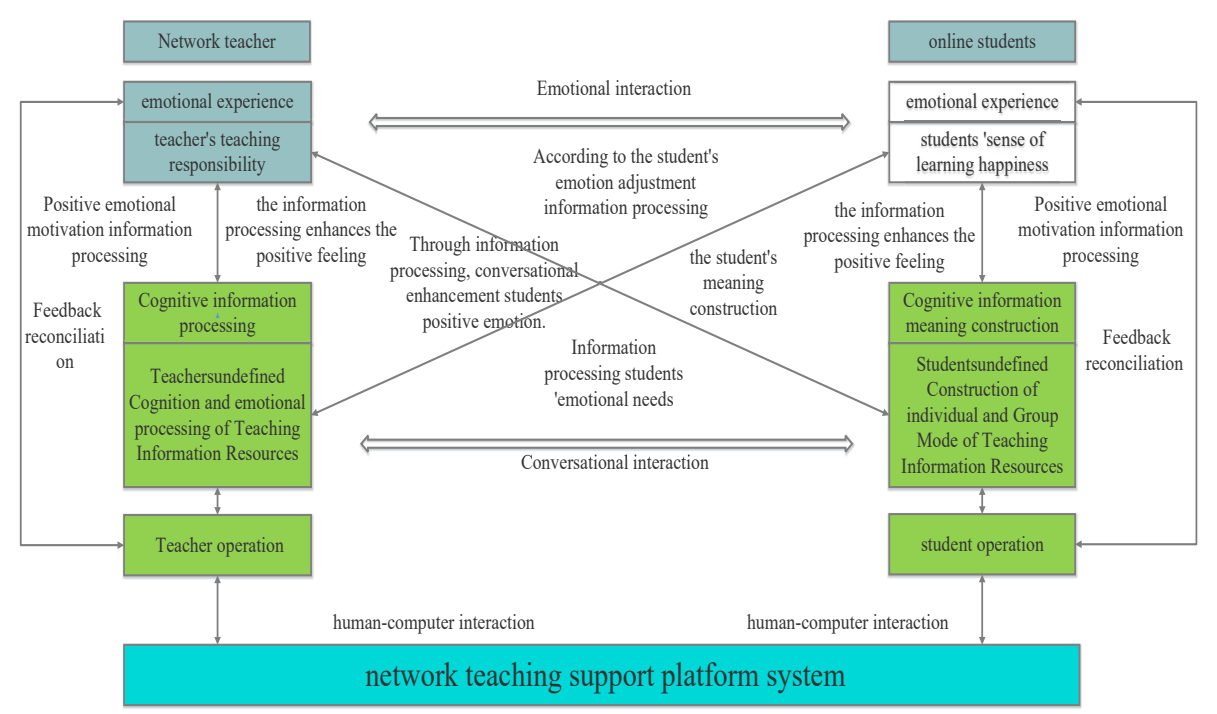

Fig. 6. "Affective and cognitive integration" network teaching mode

\subsection{Virtual simulation model based on network learning space}

Virtual simulation technology integrates multiple technologies and involves computer graphic, artificial intelligence, human-computer interaction and sensor technology. It applies multiple core technologies to achieve the environment we need and give people the feeling of being personally on the scene. Virtual reality technology implants real system in the virtual system through computer analog technology and imitates human-computer conversation in reality. It is a kind of advanced virtual simulation generated by simulation and virtuality. The entity may be a simulator or a set of complete virtual simulation system. These entities act in the set virtual simulation system so as to embody the true features. For the course of Exercise Physiology, the application of virtual simulation system has advantages in three aspects. Firstly, virtual simulation experiment system replaces the entity, and the experiment no longer consumes consumables or produce wastes, which not just reaches the purpose of learning but also embodies energy conservation and environmental protection awareness. Secondly, students' experiment process and times are no longer restricted. For the problematic experiments or the processes hard to understand, repeated operations can be achieved, which can help students consolidate knowledge and improve experiment skills. Thirdly, the improvement of virtual simulation technology also means students' improvement. Students can carry out expanded learning through this platform, without the limitation of materials and space. Even, students can study after class. It thus can be seen that, virtual simulation technology platform creates learning space and improves students' learning interest. The process of constructing virtual simulation technology and applying it in the experiment goes through primary stage, module establishment stage and model application stage. Students know well and cognize the system to reach the state of human-computer integration. Then, the 
knowledge module is implanted in the virtual simulation system according to the demands of students and course arrangement. The final stage is module application stage. This stage aims to carry out basic experiment through the knowledge learned, apply and develop knowledge of somatology and exercise physiology. This stage is crucial. The results differ a lot according to different understanding. Virtual simulation technology as a scientific teaching mode with innovativeness can effectively improve interestingness of Exercise Physiology and learning visibility so that students well promote their specialty, enhance their understanding of experimental curriculum and boost learning effect of Exercise Physiology.

\subsection{Specialty development mode based on network learning space}

Specialty development refers to the process where one gradually becomes the expert from a green hand in terms of specialized knowledge, skills and values of an industry. Network learning space can easily gather the persons of the same occupation together for exchange and learning and form a team invisibly. Specialty development mode based on network learning space under the perspective of ubiquitous learning is shown in Fig. 7.

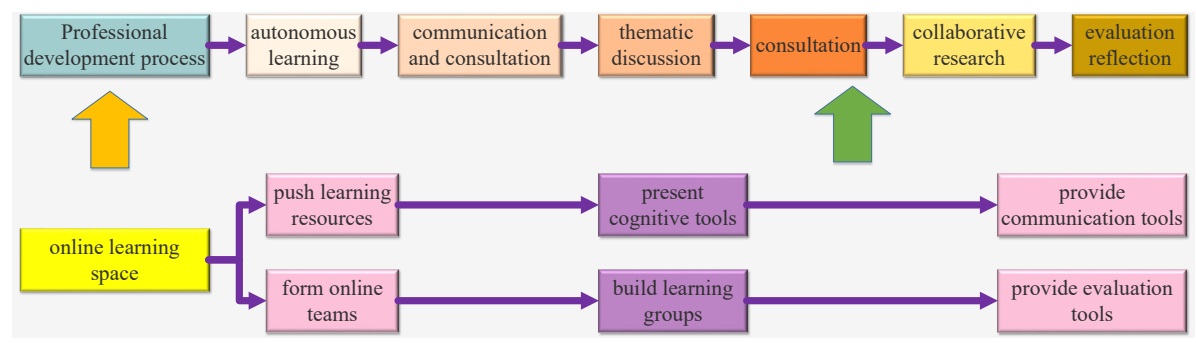

Fig. 7. Specialty development mode based on network learning space

The mode can be divided into six processes: independent study, exchange and consultation, special discussion, consultation and exchange, collaborative research, and evaluation and introspection. Firstly, with strong autonomous learning ability, professionals can utilize relevant resources and the platform for learning and study. Secondly, when professionals are confronted with the problems which cannot be solved, they can exchange, consult and discuss to solve problems, gain different understanding and view knowledge and specialty from multiple levels and perspectives. Thirdly, special discussion. When the similar problems are met in the platform, special topic can form spontaneously for discussion and exchange so as to reach full understanding of knowledge. Fourthly, professionals can consult and exchange with the experts in the field to gain more professional guidance. Fifthly, for the complex and comprehensive theme, the collaborative team can be built to solve problems by dividing the work. Sixthly, evaluation and introspection stage. The knowledge acquired needs to be repeatedly examined, corrected and adjusted. Specialty development mode based on network learning space is of great guiding significance for professionals with occupational qualification. 


\section{Teaching Effect}

Exercise Physiology as a branch of human physiology aims to study development and change laws of functions in one exercise training or repeated exercise. It is one of important basic theoretical courses of PE major in sports colleges. The course involves theory and basic application. The course has important teaching significance and social significance in the aspects of developing sports science theory, strengthening PE teaching theory and method and improving athletic ability. However, this course with rich contents and strong theory is closely related to many other courses of PE major, and involves multiple disciplines such as physics, chemistry, biology, human anatomy and human physiology. In addition, it has certain requirements for logical thinking and abstract thinking, thus leading to unsatisfactory teaching effect and difficulty in grasping the knowledge. This brings certain challenges for teaching and learning. In the face of this situation, it is necessary to explore the teaching mode which adapts to current situation and reaches the ideal teaching effect. The establishment of network learning space application mode under the perspective of ubiquitous learning opens up a new way for Exercise Physiology teaching. Rapid development of internet era and organic integration provide favorable conditions for implementation and promotion of network learning space application mode. Meanwhile, teaching and network complement each other. The mode simplifies course difficulty, enhances students' learning interest and promotes teaching development of Exercise Physiology.

\subsection{Flipped classroom teaching mode}

Compared with traditional classroom, flipped classroom means the teachercentered teaching mode is flipped to student-centered learning mode. Flipped classroom refers to the change of learning mode with multiple teaching methods and with the help of network learning space. The original explanation by the teacher and homework after class are changed to pre-class micro-video study and difficulty solving under the guidance of the teacher. In this way, students really become the subject of the classroom and change to active learning from passive reception.

\subsection{Object of study}

80 students participating in flipped classroom teaching mode were chosen as the object of study. 80 questionnaires were distributed, and all questionnaires were recovered, with the recovery rate of $100 \%$.

\subsection{Research method}

Pre-class micro-video production: The teacher produced PPT and micro-vide in accordance with teaching content and course arrangement of Exercise Physiology as well as students' learning conditions to form classroom teaching video. In the aspect 
of students, the teacher sent the teaching video in advance, and required students to carefully view the video, look up materials, propose problems, formulate the solutions, exchange and discuss.

Classroom organization and planning: According to network teaching mode of flipped classroom, the teacher answered students' questions deeply from multiple perspectives, diverged students' thinking and explored students' potential based on interactions between students and the teacher. At the same time, the teacher dominated the course schedule, organized case discussion, project cooperation, consultation and exchange, and continuously enlightened students. Moreover, the teacher participated actively and formed the harmonious classroom interaction with students.

Establishment of experimental scheme: In the experiment teaching of Exercise Physiology, flipped classroom network teaching mode was applied. The teacher guided students to view the experiment video, and asked students to autonomously design experimental scheme based on the experimental project and to learn through the open exchange form, assisted students in solving the problems in the experiment and cultivated their autonomous learning habit.

\section{$5.4 \quad$ Results}

The effect of flipped classroom network application in Exercise Physiology was recorded. The investigation results are shown in Table 1.

Table 1. Investigation results of flipped classroom network application mode

\begin{tabular}{|c|c|c|c|c|c|c|}
\hline Items & $\begin{array}{c}\text { Course } \\
\text { design is } \\
\text { rational } \\
\text { and signifi- } \\
\text { cant }\end{array}$ & $\begin{array}{c}\text { Provide stu- } \\
\text { dents with } \\
\text { independent } \\
\text { learning and } \\
\text { problem solv- } \\
\text { ing ability }\end{array}$ & $\begin{array}{c}\text { Classroom } \\
\text { atmosphere, } \\
\text { improve } \\
\text { learning } \\
\text { efficiency }\end{array}$ & $\begin{array}{c}\text { Enlighten think- } \\
\text { ing, deepen } \\
\text { understanding, } \\
\text { arouse learning } \\
\text { interest }\end{array}$ & $\begin{array}{c}\text { Enhance } \\
\text { teamwork } \\
\text { awareness } \\
\text { and ability }\end{array}$ & $\begin{array}{c}\text { Teaching } \\
\text { method is } \\
\text { appropriate } \\
\text { and deserves } \\
\text { to be promot- } \\
\text { ed }\end{array}$ \\
\hline Satisfied & $98.0 \%$ & $91.9 \%$ & $93.2 \%$ & $91.5 \%$ & $96.0 \%$ & $85.2 \%$ \\
\hline Dissatisfied & $2.0 \%$ & $8.1 \%$ & $6.8 \%$ & $8.5 \%$ & $4.0 \%$ & $14.8 \%$ \\
\hline
\end{tabular}

The findings show that, flipped classroom teaching mode applied in Exercise Physiology teaching is highly satisfied from course design, independent study, classroom atmosphere, thinking enlightenment, team awareness and teaching method, and has certain promotion value. The flipped classroom improves students' enthusiasm and knowledge mastery ability. The application feedbacks provide experimental basis for feasibility of flipped classroom and lay a foundation for improving classroom quality.

\section{Conclusion}

Four application modes of network learning space under the perspective of ubiquitous learning were proposed in this study, i.e. flipped classroom mode based on network learning space, "affective and cognitive integration" network learning space mode, virtual simulation network mode and specialty development mode. The flipped 
classroom mode was chosen as the object of study, and applied in Exercise Physiology to study its teaching effect. The investigation indicated that flipped classroom teaching mode has good teaching effect in the course, enhances students' interest and improves learning efficiency and teaching quality. Therefore, it deserves to be popularized in other fields.

\section{$7 \quad$ References}

[1] Temdee, P. Ubiquitous Learning Environment: Smart Learning Platform with Multi-Agent Architecture. Wireless Personal Communications, 2014, vol. 76(3), pp. 627-641. https://doi.org/10.1007/s11277-014-1730-2

[2] Hsieh, S.W., Jang, Y.R., Hwang, G.J., \& Chen, N.S. Effects of teaching and learning styles on students' reflection levels for ubiquitous learning. Computers \& Education, 2011, vol. 57(1), pp. 1194-1201. https://doi.org/10.1016/j.compedu.2011.01.004

[3] An, F.H. Intelligence Flowing in Online Learning Space: Effective Way to Break Communication Difficulties of Teachers in Ethnic Minority Regions. e-Education Research, 2017, vol. 27(9), pp. 102-107.

[4] Hong, Y.S.T. Dynamic nonlinear state-space model with a neural network via improved sequential learning algorithm for an online real-time hydrological modeling. Journal of Hydrology, 2012, vol. 468-469(6), pp. 11-21.https://doi.org/10.1016/j.jhydrol.2012 .08 .001

[5] Morrison, M.A., Morrison, T.G., Franklin, R. Modern and old-fashioned homonegativity among samples of Canadian and American university students. Journal of Cross-Cultural Psychology, 2009, vol. 40(4), pp. 523-542. https://doi.org/10.1177/0022022109335053

[6] Vincent, H. Made Flesh: Sacrament and Poetics in Post-Reformation England by Kimberly Johnson (review). Journal for Early Modern Cultural Studies, 2016, vol. 16(3), pp. 515519. https://doi.org/10.1353/jem.2016.0035

[7] Walkington, H. Developing Dialogic Learning Space: The Case of Online Undergraduate Research Journals. Journal of Geography in Higher Education, 2012, vol. 36(4), pp. 547562. https://doi.org/10.1080/03098265.2012.692072

[8] Allen, T.T., Sui, Z.H., Parker, N.L. Timely Decision Analysis Enabled by Efficient Social Media Modeling. Decision Analysis, 2017, vol. 14(4), pp. 250-260. https://doi.org/10. $1287 /$ deca.2017.0360

[9] Peters, P., Jones, A., Winchester-Seeto, T., et al. TermFinder: creating online termbanks of technical terms for early university study. Journal of Applied Linguistics, 2009, vol. 3(2), pp. $219-248$

[10] Stenvall, J., Kaivo-Oja, J. The Cloud University Platform: New Challenges of the Cooperation in the European University System. European Integration Studies, 2012, vol. 5, pp. 39-44.

[11] Curatolo, P. INTERNATIONAL SCHOOL OF NEUROLOGICAL SCIENCES, 13th Annual Symposium of the Child Neurology Section, Venice, Italy, September 13, 2003. Journal of Child Neurology, 2003, vol. 18(7), pp. 488-493. https://doi.org/10.1177/ $\underline{08830738030180071201}$

[12] Zhu, Z.T., Guan, Y.Q. Construction framework of "Internet learning space everyone communication". China Educational Technology, 2013, vol. 23(10), pp. 1-7. 
Paper-Innovative Applications Mode of Network Learning Space in Exercise Physiology based on...

\section{Author}

Wei Liu is an associate professor in the Jinling Institute of Technology, Nanjing, China (jiekong2000@126.com).

Article submitted 2 October 2018. Resubmitted 3 December 2018. Final acceptance 13 December 2018. Final version published as submitted by the authors. 